\title{
Colorectal Cancer Screening: Is there a Role for Stool DNA Testing?
}

\author{
Laura Mazilu*, Andra-lulia Suceveanu, Irinel-Raluca Parepa and Doina-Ecaterina Tofolean
}

Faculty of Medicine, Ovidius University, Clinical Emergency Hospital of Constanta, Romania

*Corresponding author: Laura Mazilu, Department of Oncology, Clinical Emergency Hospital of Constanta, Tomis Blvd. no. 145, 900591, Romania, Tel: 0241503444 ; E-mail: lauragrigorov@gmail.com

Received date: Mar 01, 2014, Accepted date: May 24, 2013, Published date: May 31, 2013

Copyright: ( 2014 Mazilu L, et al. This is an open-access article distributed under the terms of the Creative Commons Attribution License, which permits unrestricted use, distribution, and reproduction in any medium, provided the original author and source are credited.

\begin{abstract}
Colorectal cancer ( $\mathrm{CRC})$ is a major cause of morbidity and mortality throughout the world, being the third most common cancer in the world and the fourth most common cause of death. In recent years increased rates of CCR incidence has been reported in developing countries. The presence or absence of screening programs is an important factor in determining overall changes of CRC epidemiology. CCR screening modalities vary throughout the world, and the differences are probably due to the cost and availability of diagnostic resources. Colonoscopy, sigmoidoscopy, and FOBTs are all recommended screening tests, but adherence rates are low. Additional stoolbased methods that offer more options for CRC have been developed, including fecal DNA tests. Stool-based DNA testing is noninvasive, and it is more sensitive and specific than FOBTs, only a single stool sample is needed, the test does not require diet or medication restrictions, and it evaluates the whole colon and rectum. The disadvantages of stool-based DNA testing include: high cost, lower sensitivity comparing with colonoscopy, and the fact that if the stool-based test is positive, colonoscopy needs to be done anyway. Finally, relatively high rates of false-positive and false-negative results limit the accuracy of these tests, thereby restricting their widespread use.
\end{abstract}

Keywords: Colorectal cancer; Screening; Stool DNA testing

\section{Mini Review}

Colorectal cancer (CRC) is a major cause of morbidity and mortality throughout the world, being the third most common cancer in the world and the fourth most common cause of death, with nearly 1.4 million new cases diagnosed in 2012 [1,2].

CRC affects men and women almost equally and it accounts for over $9 \%$ of all cancer incidence, but the incidence significantly varies $[1,3]$.

It is predicted that worldwide the number of cases will rise to 1.36 million for men and 1.08 million for women by 2035. In 2012 there were about 746,000 cases diagnosed in men and 614,000 cases in women. Approximately 2.4 million cases of colorectal cancer will be diagnosed annually worldwide by 2035 [2].

In recent years increased rates of CCR incidence has been reported in developing countries, countries which previously showed a decreased risk of CRC [1].

Although, in many regions of the world, data regarding risk factors for CRC are limited, increased rates of CRC incidence reported in developing countries in economic transition, and in other countries of Eastern Europe, are likely the result of increasing prevalence of obesity associated with a western-type lifestyle, including increased consumption of high calorie foods, and physical inactivity [4-7]. In addition, the high prevalence of smoking, reported by increased rates of lung cancer mortality (which in developing countries have exceeded the mortality rates from developed countries, such as the U.S.) [3], may play an important role in the increased incidence of CRC in developing countries.

The presence or absence of screening programs is an important factor in determining overall changes of CRC epidemiology, because screening increases short term incidence of CRC, by increasing CRC diagnosis, and reduces long-term incidence of CRC by premalignant lesions treatment [8]. For this reason, CRC screening programs decreases mortality, by decreasing the incidence and by increasing the diagnosis of early-stage curable tumors [9-11]. In fact, the increased use of screening has been cited as one of the most important factors responsible for the recent decline in incidence and mortality rates of CRC in the U.S. $[12,13]$.

CCR screening modalities vary throughout the world, and the differences are probably due to the cost and availability of diagnostic resources, which directly influences the design of screening programs. Although colonoscopy can be considered as the gold standard for CRC screening, it requires a well-trained examiner, additional costs, and is less convenient for the patient [14]. Therefore, CRC screening based on colonoscopy is less feasible in most countries, and not practical in almost all countries with limited resources. Consequently, although less sensitive than structural examinations, fecal occult-blood testing (FOBT) is a cheap and easy method, and is a feasible option for CRC screening in many countries.

The U.S. current recommendations for screening and diagnosis of adenomatous polyps and CRC in average risk adults ( $>50$ years) include either annual fecal testing with guaiac tests (gFOBT) or immunochemical-based tests (iFOBT), stool DNA test with high sensitivity, flexible sigmoidoscopy every 5 years, colonoscopy every 10 years, double-contrast barium every 5 years, or CT colonography every 5 years [13].

Structural examinations are invasive procedures that require prior preparation of the colon, and are associated with various levels of risk [10]. Therefore if the resources are not available, or patients refuse these diagnostic procedures, annual fecal occult blood test (FOBT) is recommended, including gFOBT and iFOBT. gFOBT, which is one of the most used tests, was associated with an up to $33 \%$ decrease in CRC mortality [15], but is less sensitive than structural examinations, and 
less effective in preventing CRC, as sensitivity in the diagnosis of premalignant lesions is decreased [13].

Colonoscopy, sigmoidoscopy, and FOBTs are all recommended screening tests, but adherence rates are low (44,6\% for FOBTs, 47,3\% for sigmoidoscopy/colonoscopy) [16]. Studies showed that nearly a third of the patients will refuse any form of invasive testing, but are willing to undergo noninvasive testing $[16,17]$.

Additional stool-based methods that offer more options for CRC have been developed, including fecal DNA tests [18]. Stool DNA testing detects the presence of known DNA alterations during colorectal carcinogenesis in tumor cells sheded into stool [19]. Because DNA changes may differ between colon cancers, stool DNA tests typically target multiple markers in order to achieve high detection rates. Also, because DNA markers may be present in only small quantities in stool, very sensitive laboratory methods are required. Stool DNA testing has been shown to be more effective than FOBTs at detecting CRC and precancerous polyps. The new stool DNA tests demonstrate high detection rates of early-stage CRC (52-91\% sensitivity, and $93-97 \%$ specificity) [20], but no clinical trials have evaluated the impact of fecal DNA testing on patient management or CRC-related mortality. Also, there is no published evidence regarding the appropriate interval between screening stool DNA tests, although a 5 -year interval is currently recommended [20].

Stool-based DNA testing is noninvasive, and it is more sensitive and specific than FOBTs, only a single stool sample is needed, the test does not require diet or medication restrictions, and it evaluates the whole colon and rectum $[17,21]$.

The disadvantages of stool-based DNA testing include: high cost (\$400-800), lower sensitivity comparing with colonoscopy, and the fact that if the stool-based test is positive, colonoscopy needs to be done anyway. Finally, relatively high rates of false-positive and falsenegative results limit the accuracy of these tests, thereby restricting their widespread use $[17,21]$.

A recent study [22] evaluated the performance characteristics of a multitarget stool DNA (molecular assays for aberrantly methylated BMP3 and NDRG4 promoter regions, mutant KRAS, $\beta$-actin, and an immunochemical assay for human hemoglobin) in the detection of CRC. The secondary aims of the study were to determine the performance of the DNA test in the detection of advanced precancerous lesions and to compare it with a commercially available fecal immunochemical test (FIT) for human hemoglobin in the detection of both CRC and advanced precancerous lesions. The sensitivity of the DNA test for the detection of both CRC and advanced precancerous lesions exceeded that of FIT by an absolute difference of nearly $20 \%$, but FIT was more specific for the detection of both CRC and advanced precancerous lesions. The conclusion of the study was that a stool test combining altered human DNA and fetal hemoglobin showed higher single-application sensitivity than a commercial FIT for both CRC and advanced precancerous lesions, although with lower specificity [22].

Results of clinical trials indicate that fecal DNA testing can detect precancerous and cancerous colorectal lesions with moderate to high accuracy, especially when multiple mutations and DNA abnormalities are assessed. However, the evidence is too limited to fully evaluate diagnostic performance and, to date, as we already mentioned, no clinical trials have evaluated the impact of fecal DNA testing on patient management or CRC-related mortality [20,23].
NCCN guidelines stipulates that for patients unwilling or unable to have screening colonoscopy, there is increasing evidence that a stool DNA test may provide a valuable noninvasive option, but more research is necessary to determine the optimal testing interval. Only one stool DNA test, ColoSureTM, is currently available in U.S., however, stool DNA testing has not yet been approved by the FDA, and is currently not considered a first-line screening tool [19].

In conclusion, although fecal DNA testing is commercially available, it is not yet ready for prime time. An important fact to remember is that the majority of Americans are never screened for CCR despite long-standing, although imperfect, screening methods, due to the fact that there is no universal medical record system to allow better tracking of patient care, and there is no sufficient public education programs to encourage patients to utilize preventive care services, and thus to benefit from early cancer diagnosis. These issues are the true challenges that are currently faced in eradicating CRC [24].

Detection of precancerous and early-stage CRC is central to improving patient prognosis. Recommendations, guideline's and CRC screening programs vary widely around the world. Most countries have national screening programs using FOBTs, although few countries (Poland and Germany) [25] are using colonoscopy. However, most screening programs are not national and many countries in North America and Europe are performing screening pilot programs intended to assess the potential for screening implementation [26-28]. These pilot studies are using a variety of screening assays, alone or in combination (FOBTs, colonoscopy, and flexible sigmoidoscopy).

Because CRC mortality rates are increasing in developing countries, especially in those in transition, who have adopted a western-type lifestyle, or have aging populations, it is likely that implementation of CCR screening strategies will become a priority.

\section{References}

1. Haggar FA, Boushey RP (2009) Colorectal cancer epidemiology: incidence, mortality, survival, and risk factors. Clin Colon Rectal Surg 22: 191-197.

2. Romaguera D, Vergnaud AC, Peeters PH, van Gils CH, Chan DS, et al. (2012) Is concordance with World Cancer Research Fund/American Institute for Cancer Research guidelines for cancer prevention related to subsequent risk of cancer? Results from the EPIC study. Am J Clin Nutr 96: 150-163.

3. Center MM, Jemal A, Ward E (2009) International trends in colorectal cancer incidence rates. Cancer Epidemiol Biomarkers Prev 18: 1688-1694.

4. Popkin BM (2004) The nutrition transition: an overview of world patterns of change. Nutr Rev 62: S140-143.

5. Baillie K (2008) Health implications of transition from a planned to a free-market economy--an overview. Obes Rev 9 Suppl 1: 146-150.

6. Chrzanowska M, Koziel S, Ulijaszek SJ (2007) Changes in BMI and the prevalence of overweight and obesity in children and adolescents in Cracow, Poland, 1971-2000. Econ Hum Biol 5: 370-378.

7. Knai C, Suhrcke M, Lobstein T (2007) Obesity in Eastern Europe: an overview of its health and economic implications. Econ Hum Biol 5: 392-408.

8. Citarda F, Tomaselli G, Capocaccia R, Barcherini S, Crespi M; Italian Multicentre Study Group (2001) Efficacy in standard clinical practice of colonoscopic polypectomy in reducing colorectal cancer incidence. Gut 48: 812-815. 
Citation: Mazilu L, Suceveanu AI, Parepa IR, Tofolean DE (2014) Colorectal Cancer Screening: Is there a Role for Stool DNA Testing? . J Carcinog \& Mutagen S10: 006. doi:10.4172/2157-2518.S10-006

Page 3 of 3

9. Hewitson P, Glasziou P, Watson E, Towler B, Irwig L (2008) Cochrane systematic review of colorectal cancer screening using the fecal occult blood test (hemoccult): an update. Am J Gastroenterol 103: 1541-1549.

10. Walsh JM, Terdiman JP (2003) Colorectal cancer screening: scientific review. JAMA 289: 1288-1296.

11. Baxter NN, Goldwasser MA, Paszat LF, Saskin R, Urbach DR, et al. (2009) Association of colonoscopy and death from colorectal cancer. Ann Intern Med 150: 1-8.

12. Espey DK, Wu XC, Swan J, Wiggins C, Jim MA, et al. (2007) Annual report to the nation on the status of cancer, 1975-2004, featuring cancer in American Indians and Alaska Natives. Cancer 110: 2119-2152.

13. Levin B, Lieberman DA, McFarland B , Smith RA, Brooks D, et al. (2008) Screening and surveillance for the early detection of colorectal cancer and adenomatous polyps, 2008: a joint guideline from the American Cancer Society, the US Multi-Society Task Force on Colorectal Cancer, and the American College of Radiology. CA Cancer J Clin 58: 130-160.

14. Winawer SJ (2007) The multidisciplinary management of gastrointestinal cancer. Colorectal cancer screening. Best Pract Res Clin Gastroenterol 21: 1031-1048.

15. Mandel JS, Bond JH, Church TR, Snover DC, Bradley GM, et al. (1993) Reducing mortality from colorectal cancer by screening for fecal occult blood. Minnesota Colon Cancer Control Study. N Engl J Med 328: 1365-1371.

16. Deenadayalu VP, Rex DK (2004) Fecal-based DNA assays: a new, noninvasive approach to colorectal cancer screening. Cleve Clin J Med 71: 497-503.

17. Leard LE, Savides TJ, Ganiats TG (1997) Patient preferences for colorectal cancer screening. J Fam Pract 45: 211-218.

18. Ned RM, Melillo S, Marrone M (2011) Fecal DNA testing for Colorectal Cancer Screening: the ColoSureâ,„ $₫$ test. PLoS Curr 3: RRN1220.
19. NCCN Guidelines Version 2.2013. Colorectal Cancer Screening.

20. National Medical Policy. DNA Analysis of Stool to Screen for Colorectal Cancer. Policy Number: NMP106. Updated: July 2005, July 2006, August 2007, April 2008, March 2009, April 2010.

21. Kanthan R, Senger JL, Kanthan SC (2012) Fecal molecular markers for colorectal cancer screening. Gastroenterol Res Pract 2012: 184343.

22. Imperiale TF, Ransohoff DF, Itzkowitz SH, Levin TR, Lavin P, et al. (2014) Multitarget stool DNA testing for colorectal-cancer screening. N Engl J Med 370: 1287-1297.

23. WellCare (2013) Fecal DNA test for colorectal cancer. Policy Number: HS-040

24. Imperiale TF, Ransohoff DF, Itzkowitz SH, Turnbull BA, Ross ME; Colorectal Cancer Study Group (2004) Fecal DNA versus fecal occult blood for colorectal-cancer screening in an average-risk population. $\mathrm{N}$ Engl J Med 351: 2704-2714.

25. West NJ, Boustière C, Fischbach W, Parente F, Leicester RJ (2009) Colorectal cancer screening in Europe: differences in approach; similar barriers to overcome. Int J Colorectal Dis 24: 731-740.

26. Benson VS, Patnick J, Davies AK, Nadel MR, Smith RA, et al. (2008) Colorectal cancer screening: a comparison of 35 initiatives in 17 countries. Int J Cancer 122: 1357-1367.

27. Classen M, Lambert R; International Digestive Cancer Alliance (2008) Colorectal cancer screening in europe--a survey of the International Digestive Cancer Alliance between November 2004 and March 2007. Z Gastroenterol 46 Suppl 1: S23-24.

28. Pox C, Schmiegel W, Classen M (2007) Current status of screening colonoscopy in Europe and in the United States. Endoscopy 39: 168-173. 